\title{
The Research on Urban Element Design Under the Influence of Regional Culture
}

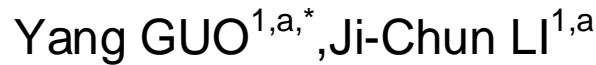 \\ ${ }^{1}$ Hubei University of Technology, No.1, Lijiadun No.1 Village, Wuchang District, Wuhan, Hubei \\ Province, China \\ a575872344@qq.com \\ ${ }^{*}$ Corresponding author
}

Keywords: regional culture, urban elements, creative design methods

\begin{abstract}
From the perspective of culture, this paper discusses the regional culture characteristics of urban element design, and points out that under the influence of regional culture, urban element design should respect and perpetuate the regional historic heritage and reflects the regional characteristics. This paper also shows the present situation of borrowing and copying phenomenon in urban element design meanwhile puts forward the creative thinking methods of regional culture characteristics in urban element design aiming at perpatuating the urban vein and promoting identifiability.
\end{abstract}

\section{Urban elements and regional culture}

Finnish architect Eero Saarinen once said, "Show your city to me, then I will tell the citizens'pursuit in culture." Urban elements is an important media in spreading the urban culture. Various street facilities and urban furniture have been essential to modern urban life. A good way of reflecting the urban culture is to utilize public facilities, a part of urban elements, the degree of perfection and aesthetic taste of which can better reflect the city's culture and spirits, and also directly show the citizens' life quality. As we all known, under the interaction of the synchronism and diachronism, different culture, customs and humane characteristics have been formed in different regions. It is the various regional characteristics that makes every city own unique landscape and cultural structures. In every detailed link of urban planning and design, especially in the urban elements design, we should do the utmost to show the native features of every city.

\section{The concept of urban elements}

Urban element, also can be called street facilities or urban furniture, refers to the objects which are used in city. Urban element, various in types and uses, is mainly divided into the following categories: transportation and instruction, such as the traffic lights, street lights, road signs, bus shelters and stalls, which are the urban furniture to meet the need of transportation; relaxation and services, such as benches, pavilions, colonnades, trash cans, mailboxes, telephone booths, fountains, clocks, billboards, pools, children's play equipments and fitness equipments, which provide a place for citizens to rest and exercise; landscapes, such as sculpturse, parterres, fountains and floor-coating, aiming at beautify the environment and decorate the urban streets. All of these are important elements in modern urban environment, the design and processing of which can reflect the civilization degree and cultural quality of the city to the full.

\section{The urban element design should show regionalism}

People always say that detials determine your success. Undoubtly, urban element, the important media of spreading messages, is a trivial thing in the background of city, which shows the scenery and features of the whole city. Therefore, urban element design should not only create the ideal living space for people, but also reflect every city's unique spirits and characters. 
When we visit a family at the first time, we can tell the tastes and preferences of the host from the details of the house, no matter the choice of furniture or a small ornament. City is just like a huge living space, where urban elements, urban furniture and street facilities are the signs of urban connotation. From the good urban element design, people can experience the cultural background and acknowledge the city. In Europe, many well-preserved towns or cities have adopted medieval elements, and the whole city is surrounded by a rich cultural atmosphere.

\section{Creative methods of urban element design under the influence of regional culture}

Certain improvements have been made in design and utilization of urban element in our country now, but there are still shortages of individuality and historic vein. When we stroll along the street of certain city and want to appreciate its beauty, we will find out that the sense of belonging to a certain region is weaker and weaker and the resemblence between cities is bigger and bigger. The skyscapers soar above the horizon everywhere, becoming a closed prison to people. Urban element design lacks of new ideas and personality. Is there a difference between the trash cans in the Confucius Temple of Nanjing and the Forbidden City of Beijing? Are there respective features of benches in Nanjing Road of Shanghai and Jianghan Road in Wuhan? Most urban element design always puts emphasis on practicability, ignoring the creativity and flexibility. At the same time, urban element design often neglects the city's historic backgtound, and blindly pursue the fashion or back-to-the-ancients trend, resulting in clone and copy everywhere. For several conditions, designers should adopt creative thinking and add new ideas, historic and cultural elements and regional features into urban element design to turn the regional culture into designing signs and make every detail rich and interesting.

\section{Condensation of regional culture signs}

\section{Digging historic culture}

Designing materials can be gathered in the process of digging historic culture of different regions. Every region possesses a large number of cultural materials, which can be found in folk tales, legends, historic celebreties, old streets, old place names and so on. What' s more, we can go to feel the old streets or lanes personally, or immerse ourselves into the villages to seek local customs and feel the loal climate, topographic features and different religions and beliefs. Precious designing materials can be gained through a great number investigation and processing. Designers should be familiar with not only the native history but also the foreign culture. Only in this way, can they digest all this information and draw from them.

\section{Forming the design elements}

If you want to combine the urban elements into local regional culture, it is necessary to go through a process from recognization to application. Firstly, designers should have a good command of local history and culture in the early stage of designning, on the basis of which historic materials are refined to form design elements. Then make these refined design elements symbolized and properly put them into urban element design. Designers should further analyze the materials after having a good command of the regional culture materials. Then they should process and integrate the regional materials into characters, which are abstract and truned into concrete image, pictures. These materials, extracting from regional characteristics such as color, forms, material quality, allusion and implied meaning, can be regarded as the raw materials about regional culture in the proccess of urban element design.

\section{Creating design symbols}

It is a significant link to symbolize the combination of the refined materials and local urban design elements. The continuity of history and culture should be endowed with creativity, deeply rooted in local traditions and possessing modern elements. Only in this way, can it be full of vitality and follow the development of the times. Therefore, the focus in the process of urban element design is the relationship between the continuity of regional culture and creativity.

Metonymy and transformation are the most commonly used methods to create the designing symbols. Metonymy refers to use the traditional symbols which signified is consistent with signifier. 
Metonymic design elements are often used in totem with a country' $\mathrm{s}$ history and civilization or symbolic meaning. There is an example: the Chinese dragon usually used in every region of China, because of its traditional symbolic meaning. Another example: the traditional Chinese garden elements such as rockery, vaze-shaped door and namental perforated window are not always thought of as symbols, but they, with typical national culture characterisitics, stand for the traditional Chinese gardens, and become the replacing symbols which can remind people of the tradition. Transformation means changing the traditional symbols. A new idea is extracted from traditional culture to satisfy the the need of modern life, and then is presented in another way to show the trditional things. If we need the simple and conceptual images replacing the complicated and concrete traditonal forms, we can simplify the traditional materials or remove the overloaded ornaments to keep the vivid and simplified structure. If we need the shock effect, exaggerating methods can be added into the traditional materials, which extremely fits for urban element such as symbolic sculptures. If we need to show the whole landscape, we can recombine the individual symbol of different times, different regions and different systems to creat a new system. The recombination, occurring in the symbols of the same kind or of different kinds, can present different effects. If the novel and vivid signs are needed, we can adopt creative ways to integrate other cultural signs such as characters, The Chinese landscape paintings, folk patterns and myths to enrich the cultural connotation of urban elements by the way of specification and formalization.

\section{Regeneration of the regional cultural symbols}

Though the traditional modeling symbol has lost its original function with the history evolution, it still contains valuable cultural symbols with the history precipitation; therefore, I still need to extend this traditional culture. Under the background of urban culture, the regional culture can be regarded as periphery carrier, while the various kinds of urban elements can directly map the regional cultural style and features. The urban elements can be seen as a measure to carry the regional characteristics, which will mix the modeling symbol with regional culture and the design of city elements together to constantly develop the regional culture. Modeling symbol is the essence of regional culture, by applying it to the real society can extend the regional culture. Fusing the modeling symbol and the city elements together will not only exhibit the real purpose of the urban element's design but also can enrich the connotation of the city programming. As to how to correctly survey the regional culture under the constantly changing aesthetic standard and visual sense, just like Jin Dijiang says: Chinese can't be only recognized by wearing the dragon robe or Peiking Opera mask. We must prolong the meaning while express the vividness on the basis of fully understanding the regional culture by taking use of the platform of modeling symbol meanwhile develop and renew the city element design under the background of regional culture. Depending on the unique long term and inclusiveness of the city elements, we can promote the mutual exchange and collision between different regional cultures.

\section{The utilization of the regional symbol}

To many people, symbol is specific while abstract. As the entitative art form, Architecture posses plenty of symbols especially under the background of the regional culture, and the urban construction will be blessed with more regional historic culture. Symbol is the most directly distinguish elements, it retrieval, progress even transform the general form of language of urban architecture to carry or transmit the customizing messages. Meanwhile, adopting the symbol to the urban element construction will increase the city element's rendering force in regional culture. There are many ways to retrieval the city element symbols, such as the space symbols, color symbols and decoration symbols. Applying all kinds of symbols into the urban element construction is a way to show the historic, traditional and even inherit the regional culture blood vessel.

\section{(1)Space symbol}

Space symbol is a kind of space form that allows people to form their own regional thoughts, because of its fixed model, it has been widely used by some filed. All of the ancient Chinese courtyard space, Patio space and space of South Korea's ancient residential buildings can be regarded as symbol that created with regional ideology and culture, which comes from people's long social practice. The urban elements design in regional culture run through the regional space symbols with specificality, 
which allows people to feel the connotation of municipal environment under the regional culture background so that people can intersect with the city.

As shown in figure one, the bus station platform awning of the JR Nishinomiya Nashino Station Square, which was designed by GK Sekkei Incorporated, Osaka Office, was designed as a bird soar to great heights in order to coordinate with the surrounding mountains, meanwhile the near square parking lot was built as well. As a spatial symbol, the platform awning modeling design has fused its geography features of surrounding mountains to make the platform more generous and beautiful, which has perfectly shown its regional environment character.

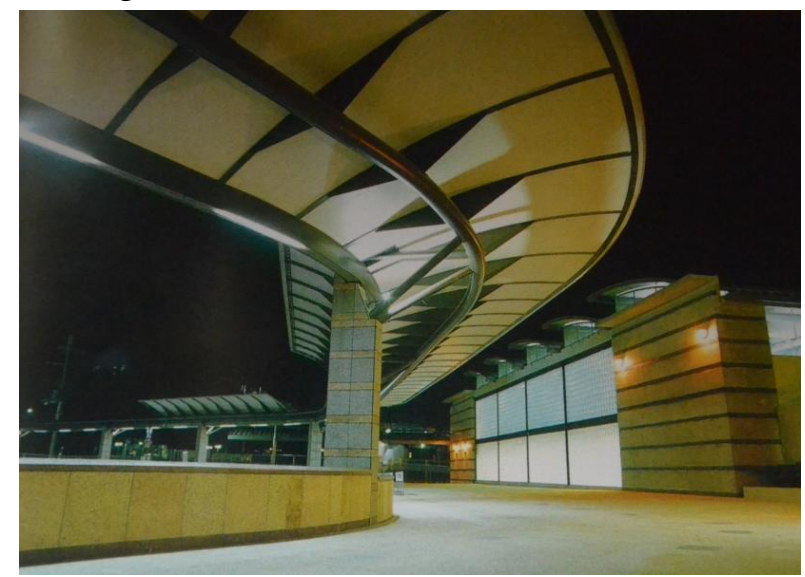

Figure 1 JR Nishinomiya Nashino Station Square

\section{(2)Color symbol}

Color will be felt by people before touch, for it can stimulates one's first visual sense. It depends on while being independent from the form, therefore color is the main manifestation mode to express the visual effect of urban element under the background of regional culture, which will embellish, express and transmit the culture. Being influenced by the custom and environment, the manifestation of color contain s the regional and national character. Color is blessed with the character of philosophy, which can reflect the aesthetic concept of national culture; therefore it has fully embodied the features of a city and its cultural ties.

Taking the regional planning methods of Xian city as an example, whose primary color was designed as grey (the color of Ming \& Qing resident's building) earthy yellow (the highland color of west area) and the terra-cotta-colored( reconciciation between the two colors), all of them are the color which can represent Xi' an style. Xi' an takes the plumpness and the deep boldness color as its main color for environment facilities, which can not only increase the style and features of the ancient city but also can promote its urban culture appeal. Shifting to Suzhou in Jiangnan region, the architecture style turns into non-color tonal system as "white wall, black brick and gray tiles". As shown in figure 3, from the level of how the color is planted in city environmental facility construction, the outstanding brightness comparison is coordinate with the general style of the regional cultural background in Suzhou, which has stressed the urban cultural characteristic while unify and coordinate with the city architecture.

There are numerous similar examples, which accounts for that color symbol in the regional cultural of city environment comes out of the long accumulating of history development, social change and cultural variation, which is the fundamental color key that contains the city cultural features.

The architect's idea comes from the basis of respecting the original features of the regional culture and then favorably melting into the keynote of color symbol. Each tourist will be deeply attracted by this special color effect and can strongly feel the city is filled with the implication of regional culture while passing by. 


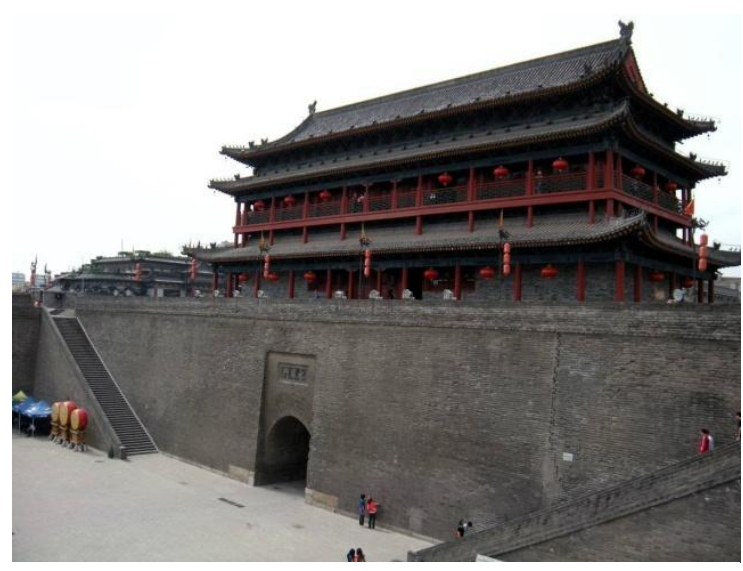

Figure 2 Fortification of Xi' an

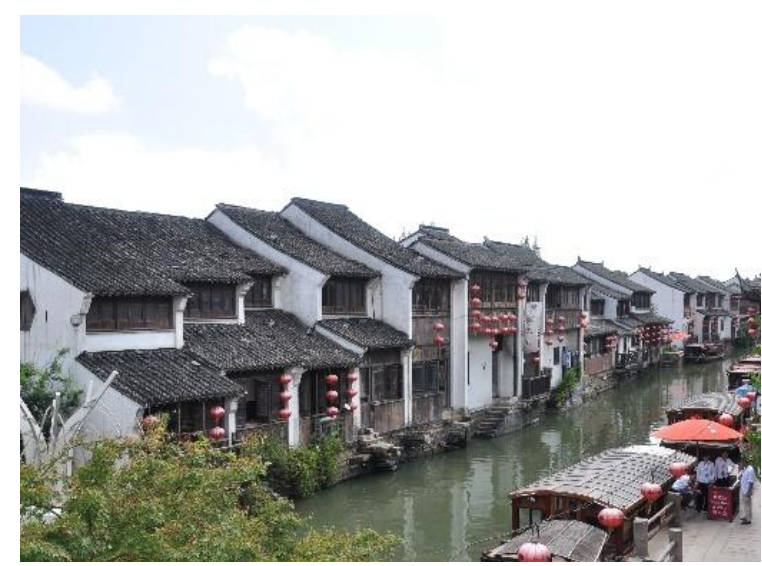

Figure 3 Shantang Street in Suzhou

(3)Decorative symbol

Decoration is one of the urban element design in regional culture, the environment decoration can reflected its relevant design achievements meanwhile the art effect, urban decoration depends on environment and render the art plays a greater effect, among which decoration is the most beautiful language. The city's decoration symbol is expounded as the symbolic elements as the city development, which contains the city's national characteristic and regional characteristic. There are plenty of decorative symbols and various kinds of window appliqué design in the environment of Suzhou Garden, among which the theme of painting of flowers and scenery are in the majority; meanwhile, there are also the content of character, music and history. As shown in figure 4-7, the city decoration material which is divided by the geometric shape and the natural type always interpenetrate with each other. Such kind of urban decoration material and its specific element characteristic has become a necessary content in Suzhou's element design and construction.

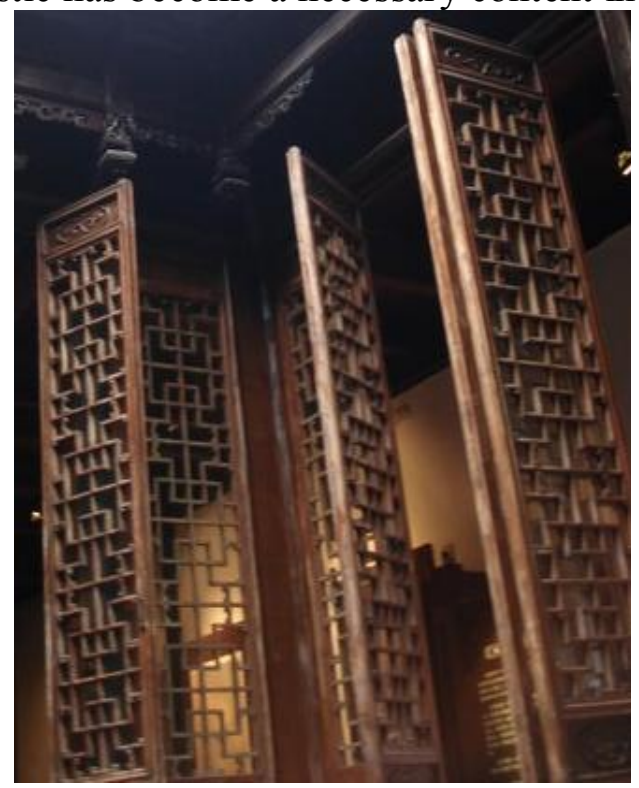

Figure 4

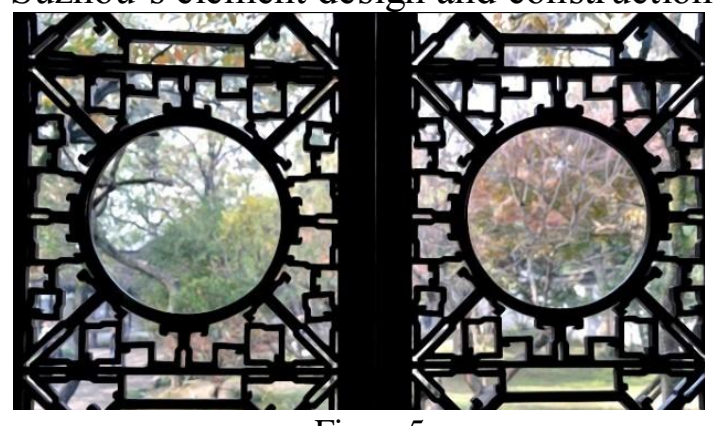

Figure5

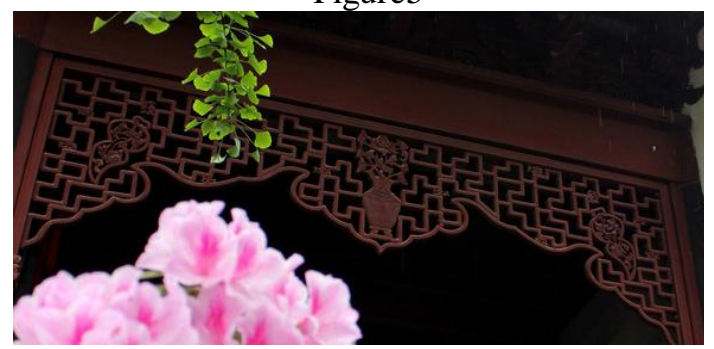

Figure6

Figure 4\&5\&6 Doors and Windows Decoration Patterns in the History of Cultural Streets in Suzhou 


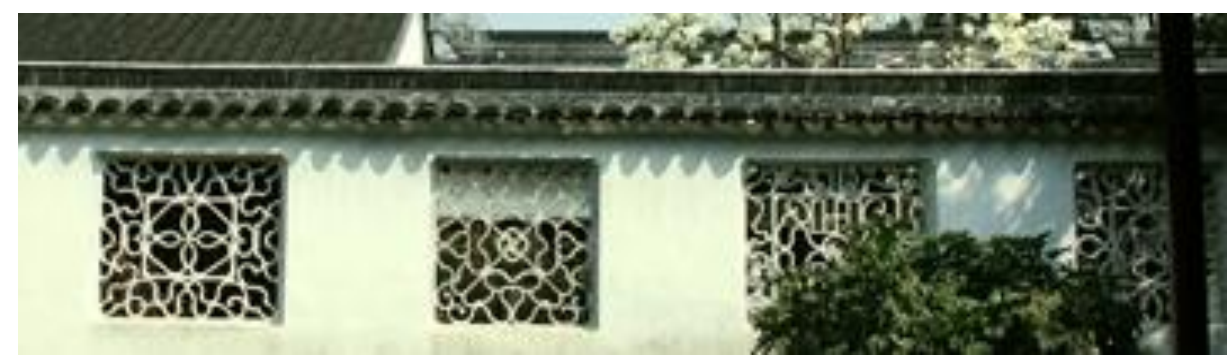

Figure 7 Doors and Windows Decoration Pattern in Suzhou Garden

\section{The utilization of urban pattern}

Urban pattern is frequently used in regional culture's element design, pattern element always seen as the easiest art measure to show the city's regional cultural character; meanwhile it can be grafted into the ordinary decoration effect. The urban pattern not only contains the visual effect that the original sample show to people, its recessive meaning can also become the magic winning weapon which is very popular among people. From ancient to now, people all longing to feel the beautiful things, so the patterns with beautiful token is also available in the urban element design meanwhile it can reflect the connotation of the modern people.

As shown in figure $8 \& 9$, the design of city streets lamp in Suzhou absorbed the "Hui" pattern in national culture, which has show its strong art penetration force without losing its function. In figure 10 , the ground spelling is also evolved from the traditional pattern. The design pattern is very elegant; it not only bears its surroundings but also added the attraction of the static facilities. Besides, the character of "Hui" means big fortune and good profits in Jiangzhe's traditional culture, which was called as "constantly prosperous and rich" in Suzhou. Therefore, by melting into the design of regional urban environment facility, such kind of design will vividly shows its regional character from the form of shape and its content connotation. The pattern we stated before is always interdependent in the urban element design. Retrieval the original character of the traditional architecture and environment facility design which is connected with the urban pattern element, we can see the elements no matter the form and content, connotation and thought are all well melted into the design. Such kind of coexistence multiple designs can not only increase the visual appealing but also can pass the design thoughts, improve the city's cultural accumulation.

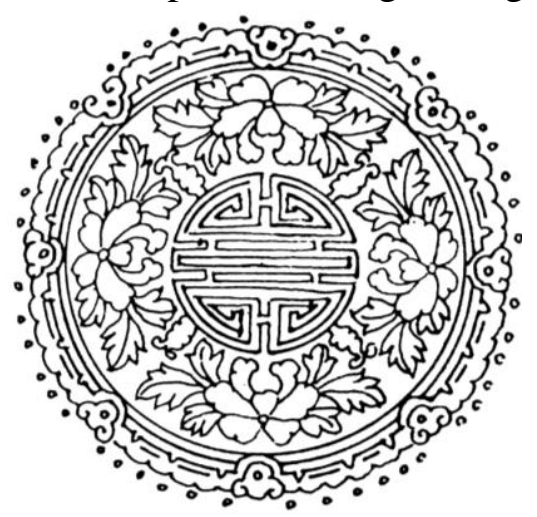

Figure 8 Traditional Auspicious Pattern

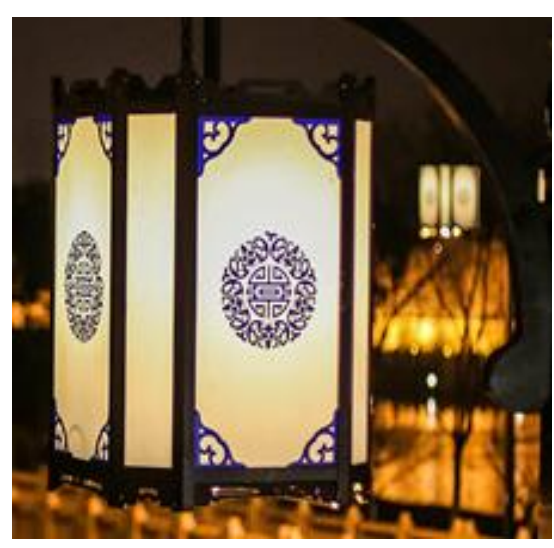

Figure 9 Lamp in Suzhou Streets

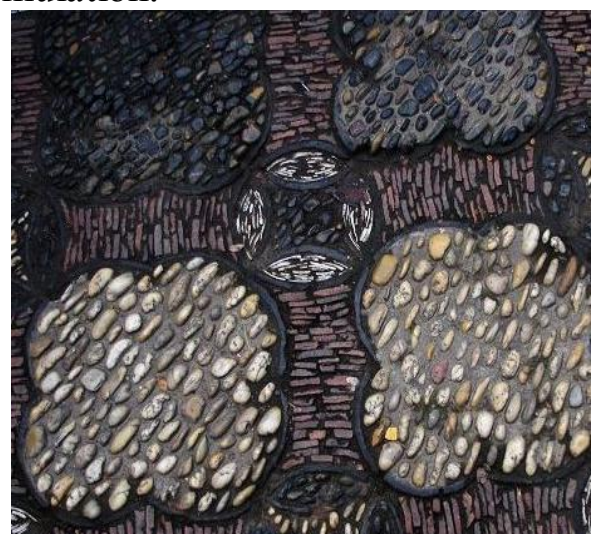

Figure 10 the Floor Decoration of Historical and Cultural Blocks in Suzhou

\section{The utilization of the traditional cultural symbols}

Traditional culture was generated from different historical periods, cultural background and different life customs by certain nations, and then it was accumulated, inherited and transformed in different social development stages, finally form various periods of different cultures. As one of the important components in regional culture, the traditional culture is an indispensable spirit product in this area or nation. Our country is blessed with plentiful of traditional culture, distinctive features, 
which was mainly reflected in clothing, etiquette, production, livelihood and the daily life behavior ect. The various kinds of material characteristics have added different kinds of art style to the urban element design. For example, the lamp in front of the Beijing streets, gives people an extraordinary experience after the innovative design. ( As shown in figure $11 \& 12$ ). The Rattle-drum is one of the oldest and traditional toys in Chinese history, which was originated from Song dynasty and was regarded as the selling tool by merchants. It looks like a tank, very unique on both sides, like a strap, handling the drum roll handle, the strap will flap on its surface and send out voice. Right now, by melting this kind of modeling into the lamp design, we have achieve the complementary en vironment effect with the territory style and features in the front gate pedestrian streets, meanwhile can remind the citizen's plenty of wonderful memorizes. The lighting design is very unique, besides its original functional use, there is art element and finally reach the harmony between human and the city culture.

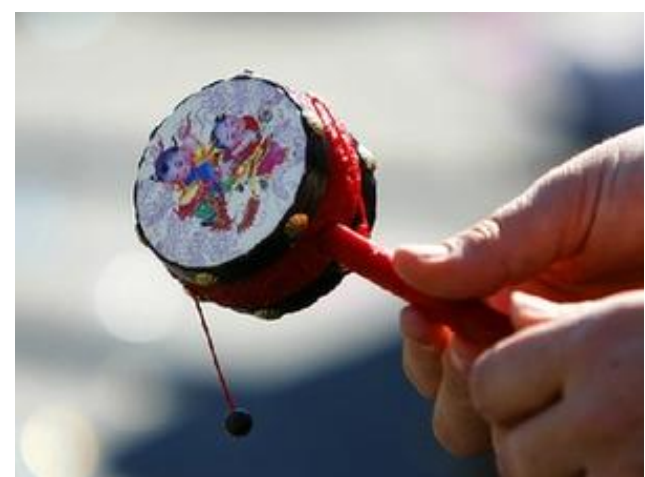

Figure 11 Rattle-drum in Folk Arts and Crafts

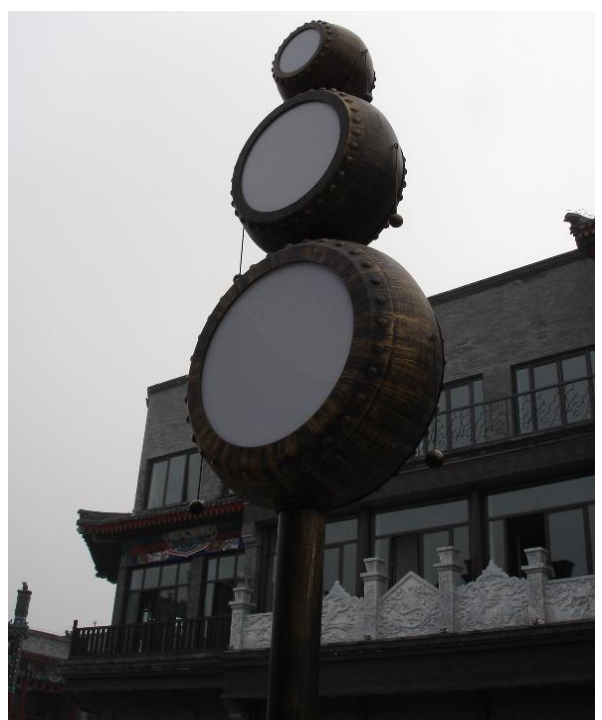

Figure 12 the Rattle-drum Lighting Facilities of Qianmen street in Beijing

\section{Conclusion}

Urban element design has reflected a sort of territorial features and the urban characteristic during its development process, it is the foundation of a city's existence and development, meanwhile the intrinsic motivation to make progress while the precious treasure for the city's progressing and development. As a part of the city landscape environment, the design considerations of city element have became a new life for the urban environment and being the carrier to transmit the regional features. The designer should seek for the integrating point for the urban element and the regional culture to establish and integrate the urban element design method that has melted the urban cultural features and finally turn it into the design symbols. By using the urban element carrier, transmit the urban culture, shaping the urban images and improve the quality of urban landscape environment.

\section{References}

[1] (Spanish) Joseph, Sarah, Urban Elements, Dalian University of Technology Press, 2001.

[2] Edited by (Japan) Pictorial editorial office, Japan's landscape design series 4 urban streets furniture design, Liaoning Science and Technology Press, Oct. 2003.

[3] Chen Ganhui, Regional culture and urban design, School of Architecture in Tsinghua University, authority talking for the urban planning

[4] Zhang Linhai, Dong Ya, Urban Space Element, Beijing: China Building Industry Press, 1986. 